\title{
Editorial
}

Dermatology

Published online: January 26, 2010

\section{The Skin Is a Site of Long-Term Viral Persistence Associated with Retention of Antiviral Memory T Cells}

\author{
Tetsuo Shiohara Yoshiko Mizukawa Yoko Kano \\ Department of Dermatology, Kyorin University School of Medicine, Tokyo, Japan
}

In this issue of Dermatology, Bonvicini et al. [1] demonstrate that human parvovirus B19 (B19) DNA can be detected not only in pityriasis lichenoides lesions, but also in healthy control skin without clinical symptoms at equivalent frequencies [2]. More importantly, they show that B19 DNA can be detected more frequently in skin samples from young individuals ( $\leq 20$ years old) than in those from older ones. These findings indicate that B19 DNA can be universally detected in the skin following primary infection, particularly in young immunocompetent individuals, regardless of whether they have symptoms, and suggest that human skin cells may be persistently infected with B19 for a long period after primary infection despite the appearance of specific IgG antibodies. Indeed, according to their findings, B19 persistence would last $<20$ years after the initial infection in the half of healthy individuals. The study by Bonvicini et al. [1] is impressive, but some crucial issues warrant further investigation: the possibility that fragments of DNA instead of full virions from a past infection persist in the skin remains to be determined. In addition, it is also unknown whether or not productive replication of this virus occurs even in healthy control skin. However, normal-appearing skin is likely to harbor a variety of functional viral ge-

\section{KARGER}

Fax +4161306 1234

E-Mail karger@karger.ch

www.karger.com
(C) 2010 S. Karger AG, Basel

$1018-8665 / 10 / 2202-0186 \$ 26.00 / 0$

Accessible online at:

www.karger.com/drm nomes, but fail to produce virions; thus, different viruses may establish a latent infection in the skin and the asymptomatic recurrence would occur. Similar findings have been also reported in rheumatoid arthritis: B19 DNA is present in the inflamed joints, but is also detected in an equivalent proportion of control samples of synovial tissues [3]: these findings do not support the potential contribution of B19 in the pathogenesis of rheumatoid arthritis. Nevertheless, the finding reported by Bonvicini et al. [1] is somewhat surprising in view of the previous belief that many viruses such as B19 are fully eradicated from the host by the combined effect of the cellular and humoral immune responses generated following the primary infection. It is now clear that the previous belief needs to be reassessed.

B19 infects erythroid-lineage cells through P antigen and causes various clinical symptoms, such as erythema infectiosum $[2,4]$ gloves and socks syndrome [5], Henoch-Schönlein purpura [6], arthropathy, or transient aplastic crisis [4] in humans. In addition to blood group $\mathrm{P}$ antigens, $\alpha_{5} \beta_{1}$ integrin [7] and Ku80 autoantigen [8] have been reported to be the cellular coreceptors for B19 infection. The results of experimental inoculation of normal volunteers with this virus demonstrated that fever 
and nonspecific influenza-like symptoms occur early in the course of acute infection while cutaneous eruptions and rheumatic symptoms develop later, about 2 weeks after the initial infection, coincident with the appearance of antiviral antibodies [4]; thus, these symptoms are likely due to the formation and deposition of immune complexes in the skin and joints. Although the presence of B19 DNA in the lesions was taken as proof of the cause of the disease in most previous studies [9], it has become obvious that we cannot accept B19 as the causative agent of a given disease simply because of the mere presence. Indeed, the study by Bonvicini et al. [1] clearly indicates that the detection of B19 DNA in lesional skin by a PCR technique cannot be used as proof of the cause of the disease. How then can an etiological role of B19 be proven in a given disease? In this regard, it is important to demonstrate localization of the virus DNA or RNA in situ within the lesional skin. Indeed, although this virus exhibits a special tropism for the human erythroid progenitor, B19 transcripts, B19 protein and viral protein 1 have been shown to be present in T cells, B cells, macrophages, and follicular dendritic cells [8]. B19 RNA has also been demonstrated to be localized in situ to the cutaneous and glomerular capillary endothelium by using reverse transcriptase in situ PCR techniques [6]. We therefore have to await the result of in situ PCR studies on the direct localization of the viral DNA or RNA to various types of cells infiltrating or resident within the evolving skin lesions and healthy control skin, before discarding the possibility of an etiological role of B19 in the pathogenesis of a given disease.

While the skin contains many specialized cell types that can serve as targets for specific viruses, the skin is also a hostile environment for other viruses. Due to their specific location in the dermis and subepithelium, dendritic cells (DCs) serve to capture various invading pathogens such as HIV, human cytomegalovirus, measles virus and human herpes virus (HSV) and are able to transmit these viruses to target cells through the DC-specific Ctype lectin DC-SIGN $[10,11]$. Interestingly, HSV-infected DCs have been shown to become resistant to further maturation stimuli supplied by LPS, TNF- $\alpha$ or CD40L [12], through downregulation of the key costimulatory molecules such as CD40, CD80, CD83, and CD86. Such virusmediated downregulation of costimulatory molecules and virus-induced apoptosis would favor viral spread and persistence, although the immunoevasive mechanisms used by HSV and probably other viruses residing in the skin could be counteracted by cross-presentation of the HSV antigen contained within these apoptotic cells by uninfected bystander DCs. Varicella-zoster virus can also be transferred from DCs to infect CD4 and CD8 T cells. Mast cells located in the perivascular area are also an important member of cellular reservoirs for HIV and other viruses. Although it is generally believed that such persistence of herpesviruses and other viruses in the skin is detrimental to the host, recent studies have suggested an alternative view that HSV persistence in the skin confers a surprising benefit to the host by upregulating the basal activation state of local innate immunity against subsequent bacterial infections [13]. Because the skin is composed of heterogenous types of susceptible cells considered as potential sanctuaries of persistent infections, such as DCs, mast cells and endothelial cells, viral persistence in these cells resident in the skin might provide a means of protecting the host from more dangerous invading pathogens.

We previously demonstrated that a significant number of CD8+ T cells with the effector-memory phenotype reside along the epidermal basal layer in fixed drug eruption lesions and even in normal-appearing skin, although much less in the latter, and consistently express an activation marker CD69 [14] despite no antigenic stimuli. This finding, when combined with fact that functional $\mathrm{T}$ cell memory requires a persistent antigen, suggests that virus-specific $\mathrm{CD} 8+\mathrm{T}$ cells are selectively retained in an activated memory phenotype in the skin due to persistent low-level antigenic stimulation provided by latent viruses such as HSV and B19.

\section{Acknowledgments}

This work was supported in part by grants form the Ministry of Education, Culture, Sports, Science and Technology (T.S.), the Ministry of Health, Labor and Welfare of Japan (T.S.) and the Japanese Research Committee on Severe Cutaneous Adverse Reaction.

\section{References}

1 Bonvicini F, La Placa M, Manaresi E, Gallinella G, Gentilomi GA, Zerbini M, Musiani M: Parvovirus B19 DNA is commonly harboured in human skin. Dermatology DOI: 10.1159/000277431.

2 Brown KE, Young NS: Parvovirus B19 in human disease. Annu Rev Med 1997;48:59-67.

3 Soderlund M, von Essen R, Haapasaari I, Kiistala U, Kiviluoto O, Hedman K: Persistence of parvovirus B19 DNA in synovial membranes of young patients with and without chronic arthropathy. Lancet 1997;349:10631065. 
4 Young NS, Brown KE: Parvovirus B19. N Engl J Med 2004;350:586-597.

5 Smith SB, Libow LF, Elston DM, Berrert MRA, Warschaw KE: Gloves and socks syndrome: early and late histopathologic features. J Am Acad Dermatol 2002;47:749754.

6 Cioc AM, Sedmak DD, Nuovo GJ, Daword MR, Smart G, Magro CM: Parvovirus B19 associated adult Henoch Schönlein purpura. J Cutan Pathol 2002;29:602-607.

7 Weigel-Kellery KA, Yoder MC, Srivastava A: $\alpha_{5} \beta_{1}$ Integrin as a cellular coreceptor for human parvovirus B19: requirement of functional activation of (beta) 1 integrin for viral entry. Blood 2003;102:3927-3933.
8 Munekata Y, Saito-Ito T, Kumura-Ishii K, Huang JH, Kodera T, Ishii T, Hirabayashi Y, Koyanagi Y, Sasaki T: Ku80 autoantigen as a cellular coreceptor for human parvovirus B19 infection. Blood 2005;106:3449-3456.

9 Takahashi Y, Murai Y, Shibata S, Munakata Y, Ishii T, Ishii K, Saitoh T, Sawai T, Sugamura K, Sasaki T: Human parvovirus B19 as a causative agent for rheumatoid arthritis. Proc Natl Acad Sci USA 1998;95:82278232.

10 Burieigh L, Lozach PY, Schiffer C, Staropoli I, Pezo V, Porrot F, Canque B, Virelizier JL, Arenzana-Seisdedors F, Amara A: Infection of dendritic cells (DCs), not DC-SIGN-mediated internalization of human immunodeficiency virus, is required for long-term transfer of virus of T cells. J Virol 2006;80: 2949-2957.
11 de Jong MA, de Witte L, Boimstedt A, van Kooyk Y, Geijtenbeek TB: Dendritic cells mediate herpes simplex virus infection and transmission through the C-type lectin DCSIGN. J Gen Virol 2008;89:2398-2409.

12 Salio M, Cella M, Suter M, Lanzavecchia A: Inhibition of dendritic cell maturation by herpes simplex virus. Eur J Immunol 1999; 29:3245-3253.

13 Barton ES, White DW, Cathelyn JS, BrettMcClellan KA, Engle M, Diamond MS, Miller VL, Virgin HW: Herpesvirus latency confers symbiotic protection from bacterial infection. Nature 2007;447:326-329.

14 Shiohara T, Mizukawa Y, Teraki Y: Pathophysiology of fixed drug eruption: the role of skin-resident T cells. Curr Opin Allergy Clin Immunol 2002;2:317-323. 